\title{
Cultura e mercadoria: perspectivas do turismo comunitário na América Latina
}

\author{
Cultura y mercancías: perspectivas de turismo comunitario en América \\ Latina
}

Culture and merchandise: Community tourism perspectives in Latin

\author{
America
}

\author{
Esp. Aracelli Bianchin ${ }^{1}$ \\ Bel. Bruno César Alves Marcelino²
}

\begin{abstract}
Resumo
A mundialização do capital gerou muitos desafios para os países latino-americanos, especialmente para as comunidades tradicionais e indígenas que inseriram no mercado global. Este artigo traça um debate preliminar sobre o turismo comunitário, ferramenta do capital, que passou a integrar as atividades econômicas das comunidades tradicionais e indígenas na América Latina. Trata-se de uma pesquisa qualitativa realizada por meios bibliográficos, documentais e com coleta de dados em três comunidades indígenas em Puerto Iguazu na Argentina. Conclui-se que o turismo se apropria e comercializa o "exótico" das comunidades e também contribui com a economia local. No entanto, o diálogo entre os atores envolvidos (Estado, empresas, ONG'S e comunidades) precisa ser aprofundado, numa construção onde os protagonistas sejam as próprias comunidades para evitar a expropriação de suas culturas. Na América Latina as comunidades têm se organizado em redes e o turismo comunitário teve participação no reconhecimento das mesmas a partir de ações e criação de políticas públicas. Em Puerto Iguazu as três experiências conhecidas retratam três formas distintas de atuação do turismo e apenas uma delas vincula-se diretamente os princípios do turismo comunitário.
\end{abstract}

Palavras-chave: Turismo comunitário; cultura; comunidades tradicionais e indígenas e políticas.

\section{Resumen}

La mundialización del capital regenero muchos desafíos para los países latino-americanos, especialmente para las comunidades tradicionales e indígenas que se insirieron en el mercado global. Este articulo traza un debate preliminar sobre el turismo comunitario, herramienta del capital, que pasó a integrar las actividades económicas de las comunidades tradicionales e indígenas en la América Latina. Se trata de una pesquisa cualitativa realizada por medios bibliográficos, documentales y con coleta de datos en tres comunidades indígenas en Puerto Iguazú en la Argentina. Se concluye que el turismo se apropia y comercializa el "exótico" de las comunidades y también contribuye con la economía local. Por lo tanto, el dialogo entre los actores envueltos, en una construcción donde los protagonistas sean las propias comunidades para evitar la expropiación de sus culturas. En la América Latina las comunidades se han organizado en redes y el turismo comunitario tuvo participación en el reconocimiento de las mismas a partir de las acciones y creaciones de

\footnotetext{
${ }^{1}$ Especialista em Desenvolvimento de Grupos, especialista em Gestão Ambiental, bacharel em Turismo e mestranda em Integração Contemporânea da América Latina - PPG ICAL; Universidade Federal da Integração Latino-Americana - UNILA; Foz do Iguaçu, Paraná, Brasil; aracelli@ poloiguassu.org. Trabalho apresentado no I Seminário Latino-Americano de Estudos em Cultura - SEMLACult, Foz do Iguaçu/PR, Brasil, 2017.

${ }^{2}$ Bacharel em Produção e Política Cultural, mestrando em Integração Contemporânea da América Latina - PPG ICAL; Centro Latino-Americano de Estudos em Cultura - CLAEC e Universidade Federal da Integração LatinoAmericana - UNILA; Bolsista do Programa de Demanda Social da PRPPG - UNILA; Foz do Iguaçu, Paraná, Brasil; brunomarcelino@claec.org. Trabalho apresentado no I Seminário Latino-Americano de Estudos em Cultura - SEMLACult, Foz do Iguaçu/PR, Brasil, 2017.
} 
políticas públicas. En Puerto Iguazú las tres experiencias conocidas retratan tres formas distintas de actuación del turismo y solo una de ellas se vincula directamente a los principios del turismo comunitario.

Palabras-clave: Turismo comunitario; cultura; comunidades tradicionales y indígenas y políticas.

\begin{abstract}
The globalization of capital has created many challenges for Latin American countries, especially for the traditional and indigenous communities that have inserted the global market. This article draws a preliminary debate on community tourism, a tool of capital, which began to integrate the economic activities of traditional and indigenous communities in Latin America. This manuscript brings a preliminary debate about community tourism, a capital tool, which began to integrate the economic activities of traditional and indigenous communities in Latin America. It is a qualitative research carried out by bibliographical data, documentary and data collection in three indigenous communities in Puerto Iguazu-Argentina. Concludes that, tourism appropriates and commercializes the "exotic" of the communities and also contributes to the local economy. However, the dialogue between the actors involved (State, companies, NGOs, and communities) need to be deepened in a construction, where the protagonists being the communities to avoid the expropriation of their cultures. In Latin America, communities have been organized into networks, and community tourism has participated in the recognition of these activities through actions and the creation of public policies. In Puerto Iguazu, the three communities reported three distinct forms of tourism performance and only one of them is directly linked to the principles of community tourism.

Keywords: Community tourism; culture; traditional and indigenous communities and policies.
\end{abstract}

\title{
1. Contextualização
}

A verticalidade imposta pela colonização e mais tarde pelo liberalismo, fortaleceu o movimento de cima para baixo com foco em atender os interesses da acumulação de capital, onde vale o poder dos que se encontram acima. Na transversal desse processo está o pensamento eurocêntrico, premissa da colonialidade que reverbera até hoje nas formas de organização da vida econômica, política, social e cultural dos países latino-americanos. Tal racionalidade nutriu o desenvolvimento dos Estados Nacionais, causando efeitos negativos nos países latino-americanos, especialmente para os povos tradicionais e indígenas que além de serem massacrados, foram postos a margem na condição de subalternos. Assim, gerou-se um campo de forças, de onde emergem a busca pela sobrevivência, resistências e conflito.

Para avançar no entendimento da condição e do futuro das comunidades tradicionais e indígenas frente à conjuntura global este artigo traz à tona o debate sobre o turismo comunitário ou turismo de base comunitária (TBC), por se tratar de uma ferramenta que gera ambiguidades uma vez que, como instrumento do capital adentra as comunidades e se apropria da cultura ali existente como sua principal mercadoria e, por outro lado gera renda, atuando na sobrevivência das mesmas e também traz aportes para o fortalecimento cultural (COMAROFF; COMAROFF, 2011).

Segundo Grunewald (2003), a partir da década de 60 e 70 a antropologia iniciou um olhar crítico para o turismo, enquanto fenômeno social dentro das comunidades tradicionais. Para o autor:

Perceber essa forma de experiência turística caracterizada pela promoção do "outro" parece de extrema relevância para a antropologia na medida, principalmente, em que isso tem se configurado tanto como alternativas econômicas valiosíssimas para as comunidades turísticas quanto para a própria revitalização cultural dessas populações em si (GRUNEWALD, 2003, p.143). 
O turismo vem servindo aos antropólogos na medida em que possibilita responder perguntas socioculturais mais amplas (SALAZAR apud STRONZA, 2001), como as interações sociais que ocorrem entre turistas e comunidades. Enquanto uma atividade econômica da modernidade, o turismo promove contradições em sua prática, visto que detém a capacidade impactar paisagens e avivar culturas, ao passo que interfere nas relações e na construção de identidades, banalizando e comercializando a cultura como atrativo turístico, tanto nos aspectos tangíveis (gastronomia, souvenir, vestuário, entre outros) quanto intangíveis (modos de vida, língua, dança, rituais que viram espetáculos, entre outros). Por outro lado, é defendido como catalisador cultural na medida em que estimula que as comunidades reavivem as memórias. Além disso, do ponto de vista econômico, é tido por instituições como a Comissão Econômica para América Latina e Caribe (CEPAL, 2007, p.3) que reconhece que "el turismo puede ser útil para promover el desarrollo (...) contribuye a la atenuación de la pobreza bajo determinadas condiciones ${ }^{3 "}$. Num documento recente sobre os povos indígenas na América Latina, a CEPAL (2015, p. 35) destaca que o turismo e produção de café são instrumentos que impulsionam a econômica dos povos e geram as expressões de bem viver, afirmando que "contribuem para o melhoramento da qualidade de vida de suas famílias, geram emprego, reduzem o impacto migratório e ajudam na articulação da economia local".

O turismo em comunidades na América Latina iniciou-se por volta dos anos 80, impulsionado por fatores econômicos, sociais e políticos. Maldonado (2009) cita que o primeiro fator foi a pressão do mercado turístico, onde bancos multilaterais e ONG's apoiaram o desenvolvimento do turismo em comunidades por fomentar a preservação dos recursos naturais, a economia local, a diversificação da oferta turística e por responder à nova corrente da demanda mundial, caracterizada pela busca de vivência com povos tradicionais. Já para as comunidades o turismo é um meio de persistir na luta, surgiu de forma independente, constituído por grupos de pequenos agricultores, membros de movimentos sem-terra, comunidades de pescadores, comunidades quilombolas, entre outros, estimulados por diferentes interesses que variam desde a oportunidade de complemento da renda até lutas sociais por posse de terra.

Essa demanda mundial ganhou força com o enfraquecimento do turismo de massa, uma vez que se perde o interesse pelo "comum", ganha maior visibilidade o "diferente". Além disso, o turista mais informado, passa a ser mais exigente, busca participar e não apenas contemplar. É onde surge o chamado turismo alternativo. Assim, a demanda pelo diferente, pelo exótico, pelo desconhecido vira tendência e o capital ao enxergar na cultura um potencial, atribui a esta uma importância econômica. Como resultado, ocorreu à instalação de grandes resorts no nordeste brasileiro e em Cancún, que utilizam as referências culturais do local (gastronomia, dança e artesanatos) como elementos para compor a atratividade, e ainda empregam a comunidade como mão de obra barata (CORIOLANO, 2006).

Um outro aspecto fundamental que chama atenção para traçar o debate do turismo em comunidades é que a gênese da atividade implica no encontro com o "outro", seja esse outro tanto a comunidade quanto o turista. E quais são as intenções desse encontro? É apenas mais uma reprodução de dependência e dominação, uma nova/velha relação entre produtor e

\footnotetext{
${ }^{3}$ Estudo realizado pela CEPAL sobre o Turismo e condições sociais no Centroamérica: as experiências da Costa Rica e Nicaraguá em comunidades (2007).
} 
consumidor? O que isso agrega ou desagrega para as comunidades? E qual a relevância da atividade para o reconhecimento das comunidades perante os Estados Nacionais?

O turismo comunitário é um movimento recente que se apoia num modelo de gestão comunitário, podendo ser tratado como segmento turístico ou mesmo como estratégia de inclusão social. Em meio às distintas definições apoia-se na concepção utilizada no Brasil pela Rede Brasileira de Turismo Solidário e Comunitário $(2010)^{4}$, a saber:

\begin{abstract}
Turismo comunitário é a atividade turística que apresenta gestão coletiva, transparência no uso e na destinação dos recursos, sendo a principal atração turística o modo de vida da população local. Nesse tipo de turismo a comunidade é proprietária dos empreendimentos turísticos e existe a preocupação em minimizar o impacto ambiental e fortalecer ações [...].
\end{abstract}

De um lado estão as comunidades que passam a introduzir o turismo em suas atividades com meio para lidar com a vulnerabilidade social (MALDONADO, 2009), retomar a autonomia e valores (LEAL, 2009) e de outro os turistas que, após a II Guerra Mundial, entraram num consumo de massa de destinos popularmente conhecidos, mas logo o "comum" não se torna tão atrativo. Buscam vivenciar experiências, estimulados pela busca do diferente, pela curiosidade e encantamento do exótico. É como se o exercício anterior (da colonização), de se olhar o diferente, o exótico voltasse à tona, mas dessa vez essa a busca se dá a partir de um imaginário construído, já conhecido e com referências.

Essa pesquisa é qualitativa de corte transversal realizada por meios bibliográficos, documentais e a partir de dados coletados no estudo de caso de três comunidades indígenas Guarani em Puerto Iguazú na Argentina. A pesquisa se deu por meio da participação em visitas as comunidades M’Borore e Yriapu e ao atrativo turístico Parque das Aves em Foz do Iguaçu, o qual comercializa uma cerimônia guarani, executada pela Comunidade Indígena Jacy Porâ. Em todas as comunidades, os pesquisadores estiveram na condição de visitantes. É importante mencionar que a abordagem dessa pesquisa está direcionada para as comunidades tradicionais e indígenas ${ }^{5}$.

Este artigo apresenta um debate estruturado em dois capítulos. O primeiro traz um resumo de um estudo preliminar dos autores que traçou um debate sobre o "exótico" desde a colonização e como este serve hoje a economia das comunidades tradicionais e indígenas. Também apresenta um panorama resumido de como o turismo comunitário vem sendo um meio de reconhecer as comunidades tradicionais e indígenas na América Latina. O segundo capítulo traz observações sobre as três comunidades indígenas visitadas em Puerto Iguazu (AR) e costura os apontamentos da realidade com as diversas teorias trabalhadas no decorrer do texto.

A pesquisa deixou claro que o turismo gera mudanças e ressignificações nas comunidades onde atua. Ao compartilharem suas vidas com os turistas, essas populações estão promovendo alterações em suas percepções tanto na forma de ver e entender a sociedade, bem como na maneira de se ver enquanto membro de um grupo social e da própria

\footnotetext{
4 Projeto Bagagem (2010). Série TURISOL de Metodologias: Parte 2- Projeto Bagagem. Recuperado de http://www.turisol.org.br/wp/wp-content/uploads/2011/02/Livreto-projeto_bagagem-09-parte2-2.pdf [20 de novembro de 2016].

${ }^{5}$ Entende-se como povos e comunidades tradicionais (caiçaras, quilombolas, campesinos, entre outros): Grupos culturalmente diferenciados e que se reconhecem como tais, que possuem formas próprias de organização social, que ocupam e usam territórios e recursos naturais como condição para sua reprodução cultural, social, religiosa, ancestral e econômica, utilizando conhecimentos, inovações e práticas gerados e transmitidos pela tradição (GOVERNO FEDERAL, decreto nº 6.040, 2007).
} 
sociedade. O turismo enquanto atividade do capital se apropria da cultura para comercializála, mas não se pode deixar de reconhecer alguns efeitos positivos da atividade como, por exemplo, a autoestima da comunidade, o resgate das memórias, entradas econômicas e o reconhecimento dessas por meio da criação de políticas públicas. Todavia, o processo requer um aprofundamento do diálogo com os atores envolvidos para assegurar autonomia das comunidades e evitar a replicação da já conhecida relação de imposição de políticas que são pensadas e implantadas de cima para baixo, onde não se leva em consideração as opiniões das comunidades que serão atingidas por essas.

Os dados obtidos na pesquisa indicam que o turismo vem servindo de aporte para a economia das comunidades, como se identificou nos grupos indígenas guarani em Puerto Iguazu que se apoiam nas visitas, venda de artesanato e apresentações como forma de garantir a sua sobrevivência. Na América Latina as iniciativas que trabalham com turismo comunitário se organizam em forma de redes, numa abordagem horizontal, fomentada pelos princípios de solidariedade, da conservação ambiental, valorização da cultura e sustentabilidade dos povos, como ocorre com a Rede de Turismo Comunitário da América Latina (REDTURS).

\section{0 retorno do exótico e o contexto na América Latina}

O pensamento eurocêntrico e hegemônico compreende que cultura é igual a civilização e, qualquer povo que não se enquadre nos padrões é tido como exótico. Para Laplantine (2003) a diversidade cultural era vista como aberração. Essa divisão é um marco na história visto que se inicia no ano 1492 com a invasão da América pelos europeus e a partir do primeiro contato com os habitantes do novo continente, cria-se essa classificação do exótico. Os registros dos viajantes retratavam o "outro" como entidade, "algo" distante, difícil de definir, e assim a divisão é posta claramente entre o mundo do civilizado e o mundo do grotesco do selvagem.

Entre os séculos XVII e XVIII o grande questionamento traçado debatia se os "povos" eram seres humanos naturais ou selvagens. Para isso alguns critérios ainda eram utilizados para avaliar o "grau de humanidade" dos povos, tais como o corpo (aparência física), a alimentação e a língua, costumes. Essa é primeira perspectiva acerca do "outro" propagada no período colonial, conforme mostra do quadro 1.

\section{$1^{\circ}$ PERSPECTIVA: COLONIZAÇÃO}

\section{REJEIÇÃO}

- Outro como aberração:

- Grotesco/selvagem;

- O não civilizado;

- Princípio: repulsa e negação.

\section{ENCANTAMENTO}

- Outro como belo:

- O homem civilizado é degrado e corrompido, o selvagem é bom e puro e inocente;

- Princípio: admirar o puro, visão romântica.

Até séc. XIX prevaleceu o termo primitivo para ser referir ao "outro"

QUADRO $1-1^{\circ}$ perspectiva sobre o "outro" na colonização

\footnotetext{
${ }^{6} \mathrm{O}$ etnocentrismo afirma que há culturas boas e culturas ruins, portanto, considera que a própria cultura ou civilização é superior às demais. Por isso, fala-se em "graus de humanidade", isto é, capacidade dos povos de atingirem níveis de civilização (LABURTHE-TOLRA; WARNIER, 2003).
} 
Fonte: Laplatine (2003), elaborado pelos autores.

A rejeição nega o diferente, pauta-se no inevitável exercício de olhar e definir o mundo a partir das suas referências. O encantamento baseia-se no romantismo que compreende o homem civilizado como um ser degrado e corrompido em contraponto ao selvagem visto como bom e puro, inocente e belo. Para o autor isso é lido como duas ideologias concorrentes, porém simétricas: "a recusa do estranho apreendido a partir de uma falta, e cujo corolário é a boa consciência que se tem sobre si e sua sociedade; a fascinação pelo estranho cujo corolário é a má consciência que se tem sobre si e sua sociedade (Ibid, 2003, p. 29). Ambas perspectivas revelam visões da relação entre colonizador e colonizado e, embora diferentes, se pautam na mesma lógica de olhar e tratar o outro como objeto, ao passo que este é definido e codificado por quem olha ${ }^{7}$.

No processo histórico da evolução sobre as teorias de cultura observa-se que a teoria evolucionista se fundamentou no exercício de entender o "outro" para dominá-lo, em atendimento ao colonialismo. Boas (1964) ao levantar questionamentos acerca do "outro", contrapondo lógicas estabelecidas, funda a corrente da teoria culturalista. O pensamento de Boas buscou desmistificar a ideia da cultura a partir da raça, pois identificou que o quê se manifesta é a diversidade, "un mismo habitat pueden coexistir culturas con pautas diferentes" (MONK apud BOAS, 1964, p.9). Para o autor, as culturas são vivas e difusas, o que está no latente é a diversidade. No entanto, o culturalismo acaba alimentando o processo de nacionalização, visto que, o Estado pode controlar as comunidades tradicionais ao unificar a diversidade em uma única nação.

A formação dos Estados Nacionais complica ainda mais a sobrevivência e legitimação das comunidades, uma vez que instaura o entendimento de que esses devem se integrar ao processo de nacionalização, que tem entre suas finalidades a demarcação do território e a criação de uma identidade cultural única. A diversidade expressa pelos povos não cabe nas normas criadas para atender a "todos", a cultura no singular "impõe sempre a lei de um poder" (CERTEAU, 2012, p. 11). É preciso outra concepção centrada na cultura no plural, que reconheça e inclua as comunidades em sua diversidade.

Ao traçar uma discussão a respeito da interculturalidade (conceito a ser construído, sob o entendimento da dinâmica viva de diversas culturas), plurinacionalidade (reconhecimento de mais de uma nação num mesmo território) e decolonialidade (ruptura dos padrões impostos pela colonização), Walsh (2008) chama atenção para o exercício de repensar e refundar outras lógicas e racionalidades na organização do Estado, as quais possam reconhecer e incluir os povos e suas culturas.

Em paralelo a imposição de identidades nacionais, a resistência e a luta sempre nutriram as comunidades. É neste contexto, que emerge o turismo comunitário, pois em sua maioria as iniciativas surgiram de forma independente, constituídas por grupos de pequenos agricultores, membros de movimentos sem-terra, comunidades de pescadores, comunidades quilombolas, entre outros, estimulados por diferentes interesses que variam desde a oportunidade de complemento da renda até lutas sociais por posse de terra, que poderiam ser potencializadas por meio da visibilidade que o turismo atrai.

Em sua essência, o turismo é um fenômeno que se caracteriza pelo deslocamento e circulação espontânea de pessoas por tempo determinado e, como prática não é apenas

\footnotetext{
${ }^{7}$ A partir da era romântica e a partir da ciência da sociedade proposta por Saint Simon em 1748, os métodos para conhecer e entender o "outro" evoluem, não cabe mais a simples reflexão, é preciso observar e analisar, e interpretar as avaliações, assim surge a etnologia.
} 
econômico, é também político, social e cultural (DE LATORRE, 1992). Já o turismo comunitário apresenta algumas particularidades voltadas a garantia do bem-estar das comunidades, assim entre suas premissas, destaca-se a autogestão comunitária, a conservação ambiental e valorização dos modos de vida (REDETURISOL, 2010).

A busca pelo diferente, pelo exótico mobiliza o turismo comunitário. É como se o exercício anterior (da colonização) de se olhar o diferente, o exótico voltasse à tona, mas dessa vez essa busca se dá a partir de um imaginário construído, já conhecido e com referências. O diferente não é novo e totalmente desconhecido, ao contrário, busca-se informações a respeito do que se quer conhecer. É interessante destacar que os mesmos elementos, os ditos "graus de humanidade" que antes contribuíram para gerar a repulsa, a negação do "outro" (a partir das características físicas, sociais, linguísticas, entre outras) hoje são vistos como aspectos de atratividade, como reforça MacCannell (1992) apud Grunewald (2003, p. 147):

O foco está num tipo de etnicidade para turismo no qual culturas exóticas figuram como atrações chave: onde os turistas vão ver costumes folk no uso diário, loja para artefatos folk em bazares autênticos, ficar alerta para forma de nariz, lábios, seios e assim por diante, aprender algumas normas locais para comportamento, e talvez aprender algo da linguagem.

O contorno da percepção acerca do "outro" produzido ao longo da história é intrigante, mas será que a origem/intenção do olhar continua a mesma? Essa busca pelo diferente é tão presente que de acordo com o relatório da Organização Mundial do Turismo (2014), as chegadas de turistas internacionais aos destinos das economias emergentes da Ásia, América Latina, Oriente Médio e África dobraram seu ritmo de crescimento (4,4\% ao ano) em detrimento dos destinos com economia mais avançada (2,2\% ao ano). Esse dado revela que a busca por destinos emergentes, onde o exótico, o místico, o muito diferente ainda é vivo. $\mathrm{O}$ diferente atrai, como menciona Maldonado (2009, p.29 e 30), "a riqueza cultural se manifesta (...) com um colorido e uma expressividade (...) o fator humano e cultural da experiência é o que cativa o turista e precede a simples motivação de imersão a natureza". O imaginário construído com foco nos elementos da natureza, da rusticidade, com sabores e características próprias conferem aos espaços das comunidades tradicionais a ideia de paraíso, de local de fuga do real. Neste sentido, o exótico apresenta-se como fundamental para fomentar esse imaginário.

Inserir as comunidades no turismo implica em colocá-las na lógica do mercado. Comaroff e Comaroff (2011) tecem críticas consistentes sobre isso ao analisar diversos grupos tradicionais que praticam o turismo. Para os autores como as comunidades tradicionais, muitas vezes encontram-se em vulnerabilidade, a prática do turismo se converte em meios de autoconstrução e fonte de sustento material, isto é, "la supervivencia cultural ha cedido su lugar a la supervivencia por medio de la cultura” (COMAROFF; COMAROFF, 2011, p.38). Por isso, afirmam que a cultura se tornou um commodity, visto que anteriormente o conjunto de características e símbolos de um grupo escapava ao capital, mas hoje encontrase efetivamente inserida.

O contato com a cultura das comunidades tradicionais e indígenas geram efeitos no cotidiano destas. Conforme o aumento da frequência das visitações turísticas, pode ocorrer a substituição de atividades tradicionais (o fazer típico do artesanato, do ritual, as formas de cultivo), uma vez que o turismo estimula as comunidades a se inserirem em novos processos produtivos inerentes a demanda do capital. Conforme aponta documento da UNESCO/IPHAN (2010, p.11):

As representações se encurtam para mostrar uma série de "cenas culminantes" adaptadas para responder à demanda turística. Com frequência as formas artísticas 
tradicionais se convertem em produtos de diversão, com a conseguinte perda de importantes formas de expressão comunitária.

Aqui se coloca um outro ponto de atenção, pois entende-se que a cultura é um processo que se produz e ao mesmo tempo é produzida, "a cultura oscila mais essencialmente entre duas formas (...) de um lado é aquilo que permanece e de outro aquilo que se inventa" (CERTEAU, 2012, p.239). Para a UNESCO (2003) o Patrimônio Cultural Imaterial das comunidades manifestado no saber (tradições e expressões orais), nas representações (usos sociais, rituais e atos festivos), na relação com a natureza e nas técnicas, não é concreto e imutável, pelo contrário, recriam-se no tempo e no contexto no qual está inserido. A instituição ainda reforça que as mudanças devem atender as demandas da comunidade e não dos agentes externos. $\mathrm{O}$ turismo pode atuar engessando o processo natural de mudanças que ocorre nas comunidades tradicionais e indígenas ou pode impor um dinamismo próprio de modificações que atenda ao capital. As premissas do turismo comunitário defendem que o turismo não deve substituir atividades tradicionais, deve ser uma atividade complementar (MALDONADO, 2009).

Por outro lado, o turismo comunitário vem contribuindo para o reconhecimento das comunidades e para a promoção de políticas públicas voltadas especificamente para essas. No documentário $^{8}$ sobre as políticas de cultura na América Latina identifica-se que os elementos culturais são vistos como algo de extrema importância. Há um certo reconhecimento que facilmente vira mercadoria pelas ferramentas do capital e apelo para a chamada indústria da cultura, focando na valorização do patrimônio cultural material e no uso da cultura para servir a economia.

A cultura é considerada por muitos autores como um importante campo na relação entre o capitalismo e os Estados-Nação. Hugo Suppo e Mônica Lessa (2007, p. 223) pontuam que a cultura, entendida como um sistema de valores simbólicos e sociais, constitui-se como um fator de grande influência na política externa dos Estados-Nação, servindo como ferramenta de aproximação da sociedade, bem como geradora de conflitos (apud CARVALHO; FILHO, 2011, p. 2). Alexander Wendt (1999, apud CARVALHO; FILHO, 2011, p. 3), entende a cultura como o principal atributo na formação da identidade nacional, sendo então, um fator relevante no comportamento dos Estados-Nação e consequentemente nos processos econômicos e sociais da região. Lessa (2010, p. 50) afirma que:

Nesse sentido, a idéia de que na "globalização", ou na "pós-modernidade", como prefere Jameson (2000), a cultura não é mais uma "expressão relativamente autônoma da organização social", mas a "própria lógica" do capitalismo tardio aponta para a necessidade de se repensar o lugar da cultura a partir 1945, articulado com as expectativas, perspectivas e as disputas travadas em seu nome.

A partir da globalização e dos processos pós-modernos a cultura passa a ser vista como um mecanismo chave na manutenção do capitalismo e do Estado-Nação, ganhando espaço em seus meios de poder e consequentemente o reconhecimento dos processos culturais vivenciados pela sociedade civil no vértice do meio social. Uma forma de verificação desse reconhecimento é por meio do turismo comunitário, trazendo para dentro das comunidades tradicionais e indígenas, uma ferramenta utilizada pelo capital, para conhecer e trabalhar mercadologicamente a cultura destas. Canclini (2005) considera as políticas culturais como intervenções realizadas pelo Estado, instituições civis e grupos comunitários organizados, com o intuito de promover o desenvolvimento simbólico, satisfazendo as necessidades

\footnotetext{
${ }^{8}$ Políticas de la cultura en América Latina - documentário produzido entre os anos de 2005 e 2009. Trata-se de entrevistas com políticos, acadêmicos, artistas e técnicos culturais do México, Peru e Chile. Disponível em: https://www.youtube.com/watch?v=RnbTFCFG7y0. Acesso em 15 de maio de 2016.
} 
culturais da população e a sua transformação social. Porém, também é importante ressaltar as mazelas que essas políticas podem desenvolver para as comunidades.

O autor ainda alerta, que as políticas culturais não devem ser implementadas somente de forma local ou regional, mas devem garantir o intercâmbio e a globalização dos fluxos levando-se, em conta, o caráter transnacional dos processos simbólicos e materiais da atualidade. Em um tempo onde as indústrias culturais atravessam fronteiras nos agrupando e nos conectando de forma globalizada - fato este ligado diretamente ao trabalho feito pelo turismo comunitário que tem a função de globalizar as ações - as tradições e identidades das comunidades tradicionais e indígenas, são inseridas ao mercado e aos interessados em conhecer o "exótico" e diferente.

No campo de forças, os povos pedem pela discussão de seus direitos. No entanto, a diversidade é enquadrada aos genéricos: os negros, os índios; os caiçaras e não se atende a diversidade, conforme afirma a autora: "La colonialidad del poder se refiere al estabelecimento de un sistema de clasificación social basada en una jerárquica racial y sexual, y en la formación y distribuición de identidad sociales de superior a inferior: blancos, mestizos, indios e negros" (WALSH, 2008, p. 236).

Deste modo, caminha-se para um processo onde cristalizam-se as identidades, e "não consideram a complexidade social" (BENEDICT, 2000, p.12). Os povos são lidos como "problemas" pontuais, porém são reflexos de uma crise do sistema adotado pelo Estado Nacional. Quando os Estados unificam, automaticamente facilitam o exercício do poder. Diante desse contexto, a política mostra-se um instrumento potencial para romper com isso. Todavia, a cultura precisa ser democratizada e não mercantilizada. Para isso reconhecer a diversidade pode ser um primeiro passo e pensar essa diversidade na estrutura do Estado é um segundo.

O que chama atenção no turismo comunitário na América Latina é o movimento de implementação de políticas públicas com foco no setor econômico, mas que vem fazendo um importante papel de reconhecimento das comunidades tradicionais e indígenas. Como se trata de um movimento recente, o Turismo de Base Comunitária (TBC) caminha para um reconhecimento em muitos países na América Latina, onde está se consolidando como estratégia de desenvolvimento. Para se fortalecer identifica-se o surgimento de redes, isto é, agrupamento de atores com objetivo comum, a saber:

A ideia de rede assume frequentemente um caráter propositivo nos movimentos sociais, isto é, a rede como forma organizacional e estratégia de ação que permitiria aos movimentos sociais desenvolverem relações mais horizontalizadas, menos centralizadas e, portanto, mais democráticas (SCHERER-WARREN, 2007, p. 42)

Em 2001 foi criada a Rede de Turismo Comunitário da América Latina (REDTURS). Trata-se de uma organização que tem como premissa o desenvolvimento sustentável, a autogestão do turismo, sendo a comunidade a protagonista do seu desenvolvimento. A REDTURS é formada por comunidades campesinas e indígenas e contempla a participação de 13 países latino-americanos: Argentina, Bolívia, Brasil ${ }^{9}$, Chile, Colômbia, Costa Rica, Equador, El Salvador, Guatemala, Honduras, Nicarágua, Panamá e Peru. No Plano de Ação 2003-2010, a instituição se posicionou politicamente ao definir como eixo estratégico de desenvolvimento a garantia do reconhecimento dos direitos das comunidades indígenas e rurais nas políticas e programas de turismo ${ }^{10}$.

\footnotetext{
${ }^{9}$ No Brasil identifica-se 37 iniciativas participantes da REDTURS.

${ }^{10}$ Informações disponíveis em: www.redturs.org. Acesso em 20 de maio de 2016.
} 
O quadro 2 e 3 apresentam as principais ações e políticas públicas de reconhecimento das comunidades por meio do turismo comunitário e também mostram o número de iniciativas por países de acordo com os dados disponibilizados na plataforma da REDTURS. 
RELACult - Revista Latino-Americana de Estudos em Cultura e Sociedade

Revista Latinoamericana de Estudios en Cultura y Sociedad | Latin American Journal of Studies in Culture and Society

V. 03, ed. especial, dez., 2017, artigo $\mathrm{n}^{\circ}$ 828 | relacult.claec.org |e-ISSN: 2525-7870

\begin{tabular}{|c|c|c|}
\hline PAÍS & AÇÕES/ POLÍTICAS DE RECONHECIMENTO DAS COMUNIDADES & $\mathbf{N}^{\circ}$ INICIATIVAS \\
\hline Equador & $\begin{array}{l}\text { - } \quad \text { Reconhecimento da existência jurídica das comunidades; } \\
\text { - } \quad \text { Lei de Organização e Regime de Comunidades; } \\
\text { - } \quad \text { Federação Plurinacional de Turismo Comunitário do Equador (FEPTCE); } \\
\text { - } \quad \text { Regulamento para o Registro de Centros de Turismo Comunitários (CTC), } 2006 .\end{array}$ & $\begin{array}{l}52 \text { iniciativas } \\
\text { Reservas ecológicas, comunidades } \\
\text { indígenas, rurais e de pescadores. } \\
\text { Destaque para as etnias Chachi, } \\
\text { Afroequatoriana e Kichwa-Kañari. }\end{array}$ \\
\hline Guatemala & $\begin{array}{l}\text { - Federação Nacional de Turismo Comunitário de Guatemala (FENATUCGUA), responsável por } \\
\text { investimentos para o fomento de comunidades organizadas, por meio do apoio na elaboração de } \\
\text { projetos, marketing e gestão de fundos, coordenação de ações com instituições do Governo, ONGs e } \\
\text { no apoio a eventos; } \\
\text { - Secretaria de Turismo Comunitário (2008). }\end{array}$ & $\begin{array}{l}16 \text { iniciativas entre reservas ecológicas; } \\
\text { indígenas; comunidades rurais e sítios } \\
\text { arqueológicos. }\end{array}$ \\
\hline Costa Rica & $\begin{array}{l}\text { - Instituto de Turismo Costarriquense (ICT); } \\
\text { - Turismo Rural Comunitário como um dos quatro eixos estratégicos para o desenvolvimento do } \\
\text { turismo (2007); } \\
\text { - Lei de Incentivo ao TRC (2010) que favorece a aquisição de insumos. }\end{array}$ & $\begin{array}{l}35 \text { iniciativas } \\
\text { Destaca-se para o ecoturismo e as } \\
\text { associações de pequenos produtores rurais. }\end{array}$ \\
\hline Nicaraguá & $\begin{array}{l}\text { - Política de promoção do turismo comunitário, regula a atividade e promove a capacitação, melhora a } \\
\text { infraestrutura e trata do marketing internacional, surgiu por meio do diálogo entre a Rede } \\
\text { Nicaraguense de Turismo Rural (RENITURAL) e o setor público. }\end{array}$ & $\begin{array}{l}36 \text { iniciativas } \\
\text { Destaca-se para o ecoturismo. }\end{array}$ \\
\hline Peru & $\begin{array}{l}\text { - Plano Nacional Estratégico de Turismo (PENTUR); } \\
\text { Projeto de Fortalecimento e Desenvolvimento do turismo comunitário no Peru (TURURAL 2007- } \\
\text { 2010), com o fim de incluir os setores marginalizados no desenvolvimento da atividade turística e } \\
\text { fortalecer instituições públicas. }\end{array}$ & $\begin{array}{l}36 \text { iniciativas } \\
\text { Destaque para as etnias quéchua, aymará e } \\
\text { os uros. }\end{array}$ \\
\hline Bolívia & $\begin{array}{l}\text { - Plano Nacional de Turismo aporta para o desenvolvimento de turismo comunitário priorizando a } \\
\text { democratização dos benefícios e projetando na atividade uma estratégia para eliminar a pobreza. A } \\
\text { estratégia trabalha dois programas, sendo um de fortalecimento dos destinos comunitários e o outro a } \\
\text { criação da oferta turística indígena e comunitária em regiões de alto índice de pobreza (Ibid., p. } 40 \text { e } \\
\text { 41). }\end{array}$ & $\begin{array}{l}21 \text { iniciativas entre reservas ecológicas; } \\
\text { indígenas. Também há comunidades de } \\
\text { origem aymará. }\end{array}$ \\
\hline
\end{tabular}

Quadro 2 - Panorama Equador, Guatemala, Costa Rica, Nicaraguá, Peru e Bolívia.

Fonte: Maldonado (2009) e REDTURS (2017). Elaborado pelos autores. 
RELACult - Revista Latino-Americana de Estudos em Cultura e Sociedade

Revista Latinoamericana de Estudios en Cultura y Sociedad | Latin American Journal of Studies in Culture and Society

V. 03, ed. especial, dez., 2017, artigo $n^{\circ} 828$ | relacult.claec.org | e-ISSN: 2525-7870

\begin{tabular}{|c|c|c|}
\hline PAÍS & $\begin{array}{c}\text { AÇÕES/ POLÍTICAS DE RECONHECIMENTO DAS COMUNIDADES } \\
\end{array}$ & $\mathbf{N}^{\circ}$ INICIATIVAS \\
\hline Venezuela & $\begin{array}{l}\text { - Turismo Comunitário reconhecidos como políticas de Estado; } \\
\text { - } \quad \text { Lei de Fomento do Turismo Sustentável como Atividade Comunitária e Social (2013); } \\
\text { - } \quad \text { Assessoria técnica do MINTUR para auxiliar o desenvolvimento das Empresas Turísticas } \\
\text { - } \quad \text { Comunais (ETCs) com financiamento público e privado; } \\
\text { - Estabelecimento de convênios entre o MINTUR e as ETCs com o objetivo de ampliar a oferta turística } \\
\text { nacional com preços solidários e contribuir para o "desenvolvimento integral e racional do patrimônio; } \\
\text { - Propõe uma visão contra-hegemônica de desenvolvimento turístico. }\end{array}$ & $\begin{array}{l}5 \text { iniciativas } \\
\text { Destaca-se as iniciativas de pequenos } \\
\text { produtores rurais e indígenas da etnia } \\
\text { pemon. }\end{array}$ \\
\hline Colômbia & $\begin{array}{l}\text { - A Constituição Política Nacional de 1991, reconhece e protege a condição multiétnica e pluricultural } \\
\text { do Estado de cinco grupos étnicos, como os povos indígenas, comunidades negras e afrocolombianas, } \\
\text { Palenqueros, Raizales e Rom; } \\
\text { - Fundo Nacional de Turismo apoia a execução da Política Pública para o desenvolvimento do Turismo } \\
\text { Comunitário. }\end{array}$ & $\begin{array}{l}19 \text { iniciativas } \\
\text { Destaca-se o Ecoturismo e comunidades } \\
\text { indígenas e pequenos agricultores. }\end{array}$ \\
\hline Chile & $\begin{array}{l}\text { - Organizações comunitárias independentes que mobilizam a realização de um evento anual de turismo } \\
\text { comunitário desde 2011; } \\
\text { - Foco na comercialização. }\end{array}$ & $\begin{array}{l}6 \text { iniciativas } \\
\text { Destaca-se os indígenas como os } \\
\text { mapuches, cultura "atacameña" e } \\
\text { agricultores rurais como produtores de } \\
\text { vinho. }\end{array}$ \\
\hline Argentina & $\begin{array}{l}\text { - Estado por meio do Ministério do Turismo criou a Rede Argentina de Turismo Rural Comunitário } \\
\text { (RATURC) como parte do Plano Federal de Turismo Sustentável (2006). A rede busca fortalecer o } \\
\text { turismo comunitário, e difundi-lo como novo produto da oferta nacional; } \\
\text { - Rede de Turismo Campesino dos Valle Calchaquíes, em Salta, e a Rede Provincial de Turismo Rural } \\
\text { de Base Comunitária de Jujuy. }\end{array}$ & $\begin{array}{l}7 \text { iniciativas } \\
\text { Destaca-se os pequenos produtores rurais. }\end{array}$ \\
\hline Brasil & $\begin{array}{l}\text { - Apoio financeiro do Estado (2005-2006) após a Criação do Ministério do Turismo; } \\
\text { - Criada a Rede Brasileira de Turismo Solidário e Comunitário (Rede Turisol), composta por } 23 \\
\text { iniciativas em } 10 \text { estados brasileiros, como por exemplo: a Acolhida na Colônia, localizada na Encosta } \\
\text { da Serra Geral (SC); a Fundação Casa Grande, em Nova Olinda (CE); a Pousada Aldeia dos Lagos em } \\
\text { Silves (AM); o Projeto Saúde e Alegria, em Santarém (PA); e Pousada Uacari (RDS Mamirauá), em } \\
\text { Tefé (AM); a Rede Tucum (CE) e o Projeto Bagagem. } \\
\text { - Organizações independentes. }\end{array}$ & $\begin{array}{l}37 \text { iniciativas } \\
\text { Destaca-se comunidades rurais, indígenas, } \\
\text { caiçaras e quilombolas. }\end{array}$ \\
\hline
\end{tabular}

Quadro 3 - Panorama Venezuela, Colômbia, Chile, Argentina e Brasil.

Fonte: Maldonado (2009); REDTURS (2017), Site do Governo da Venezuela, Colômbia e Chile. Elaborado pelos autores. 
Identifica-se que muitas iniciativas apresentadas no quadro anterior surgiram por meio da organização de cooperativas e grupos familiares, da criação de áreas de conservação nos territórios das comunidades e do aproveitamento dos recursos naturais. Observa-se que os 11 países citados nos quadros apresentam ações voltadas ao turismo comunitário, como a inclusão do tema no âmbito da governança nacional do turismo, projetos de fomento e financiamento, bem como outras ações pontuais.

No plano teórico tanto na Venezuela quanto na Colômbia identifica-se duas ações consistentes. Na Venezuela a Lei Orgânica do Turismo (2012) reconhece o turismo comunitário como política pública prioritária, isso representa um passo adiante no âmbito político. O governo trabalha com critérios para o desenvolvimento do turismo que configuram um perfil contra hegemônico. Abaixo segue trecho do documento da lei onde menciona-se o turismo comunitário.

Turismo como actividad comunitaria: Es una política de Estado orientada a fomentar la participación de las comunidades organizadas en instancias del poder popular y demás formas de participación en el desarrollo y control de la actividad turística, el manejo adecuado del patrimonio natural y cultural a través del impulso de empresas turísticas de propiedad social directa e indirecta comunal y demás organizaciones socioproductivas del poder popular (VENEZUELA, 2013, p. 17).

Na Colômbia a Constituição Nacional de 1991 reconhece e protege a condição multiétnica e pluricultural da nação contemplando a existência de cinco grupos étnicos: os povos indígenas, comunidades negras ou afrocolombianas, Palenqueros, Raizales e Rom. O objetivo é dar visibilidade e reconhecimento sobre a diversidade cultural dos povos que ocupam seu território nacional, garantindo assim a criação de políticas públicas que valorizem as particularidades de cada povo e/ou etnia. O Ministério do Comércio, Indústria e Turismo reconhece o turismo comunitário nas suas linhas de atuação, aportando a seguinte importância:

fortalecer la competitividad y el emprendimiento de la población rural, campesina, indígena, mestiza o afrodescendiente, con el objeto de contribuir a mejorar la calidad de vida, el entendimiento entre las comunidades y proveer de una alternativa productiva que permite la protección del medio ambiente y el empoderamiento del patrimonio cultural.

Neste sentido, o turismo teve um efeito positivo na medida em que apoiou a reafirmação da cultura. Para Leal (2009, p.243) em seu estudo sobre turismo em comunidades indígenas, os povos têm acionado "a cultura não só como marcador de identidade, mas também como mecanismo político de retomada do controle da própria autonomia".

$\mathrm{Na}$ plataforma da REDTURS também se identificou que diversas iniciativas receberam apoio de agentes externos não governamentais e também ocorreu o incentivo financeiro externo para desenvolver o turismo comunitário. No Equador, a Fundação de Organizações de Salinas (FUNORSAL), coordena 26 cooperativas e agroindústrias e com apoio da UNICEF (United Nations Children's Fund - ONU), em 1985 Salinas de Tomabela se transformou em um destino turístico comunitário. No Peru, a Associação Huascar-Huandi formada por 8 famílias rurais foi apoiada inicialmente pela organização Moutain Institute, organização internacional de caráter não governamental que se dedica a proteção ambiental de áreas de montanhas. 


\subsection{Comparativo das iniciativas de Turismo Comunitário em Puerto Iguazu}

A Aldeia Fortin M’Borore é uma área com titulação indígena que abriga cerca de 300 pessoas. Atuam no turismo há mais de oito anos em parceria com uma operadora de turismo local. O passeio tem duração de 02 horas e custa em torno de $\mathrm{R} \$ 75,00$ por pessoa ( $\mathrm{P} \$$ 410,00), sendo comercializado pela operadora diretamente, por pacotes de viagens e por plataformas on line. A comunidade costuma receber duas visitas agendadas diariamente, ocorrendo uma pela manhã e outra pela tarde. De acordo com relatos do guia a operadora de turismo que trabalha com a comunidade realizou capacitações com as pessoas da comunidade para a formação dos guias, estruturação do roteiro do passeio, adequação de estruturas, ações precedentes para iniciar a comercialização.

A comunidade localiza-se a cerca de 800 metros da estrada principal que leva as Cataratas do Iguaçu, isto é, encontra-se no chamado corredor turístico. A operadora disponibiliza uma espécie de caminhão adaptado para o transporte de passageiros, para levar os visitantes até a aldeia. Ao chegar o guia estava posicionando aguardando os visitantes. Sorrindo, ele fez uma apresentação inicial antes de iniciar o percurso de trilha com o grupo de visitantes, agradecendo a presença de todos e explicando o quanto é importante para a comunidade receber visitantes principalmente no que se refere ao ganho financeiro que essa atividade proporciona. Ele expôs principalmente os aspectos de como vivem os guaranis ali na comunidade e disse ser uma grande alegria para a comunidade se apresentar ao público externo e demonstrarem sua cultura e seus costumes, pois essa é uma forma de se preservarem diante da sociedade. Explicou que o grupo percorreria uma trilha de aproximadamente 45 minutos de experiência, num trajeto circular que ao final haveria com uma surpresa cultural do grupo artístico da aldeia.

Trata-se de um percurso em meio a mata desenhado para atender a atividade turística. No trajeto há paradas para explicar as armadilhas utilizadas na caça, construções típicas guarani, plantas e árvores, histórico e costumes da comunidade como o cumprimento Auyervete, degustação do pão típico chamado bojapé, apresentação do coral e venda de artesanato. Trata-se de uma trilha bem elaborada para atender as expectativas dos visitantes com interações, curiosidade e venda de "souvenires". No entanto, a trilha não passa por áreas comuns da comunidade como o local sagrado da Casa de Reza, casas e outros.

Todo o trajeto é organizado e sinalizado, e todos usavam roupas da mesma cor para configurar uma espécie de uniforme. Na segunda parada uma placa entalhada em madeira saúda os visitantes com Bem-Vindos e com o nome guarani da comunidade - Peju Porãete tekoa Mbororépy, local onde o guia explicou todo o histórico, a relação com a sociedade não indígena, as parcerias firmadas com a saúde e com a educação, e principalmente a história de luta pela terra e permanência da comunidade e da importância do trabalho do cacique para estas conquistas. Durante a caminhada, em três momentos o grupo de visitantes participou de atividades interativas: um balanço em uma raiz aérea (cipó) em que o visitante é convidado a se pendurar, um prato típico (uma espécie de pãozinho) preparado e oferecido por uma indígena jovem da comunidade, uma iguaria servida com mel colhido de jataí, a mesma abelha que no início da trilha foi apresentada e explicada pelo guia. Na parada uma moça aguardava o grupo num ambiente representando uma choupana. Ela se dispôs a fazer fotos e explicar sobre o que estava sendo servido. Além da demonstração de 4 tipos de armadilhas para abater animais silvestres para alimentação da comunidade, em outras paradas do percurso. Ao final da trilha, um grupo de dança típica se apresentou com coral, instrumentos musicais e mulheres dançando. Duas músicas foram apresentadas, a primeira falando da gratidão pela natureza, e a segunda em agradecimento aos visitantes por estarem ali. $\mathrm{O}$ guia apresentou cada integrante com seu nome em espanhol e na sequência o nome em guarani. 
Por último, antes do grupo retornar ao caminhão da agência, chega-se a uma grande choupana com mesas altas onde há um livro registro para assinatura dos visitantes e a exposição de artesanato à venda. Os artesãos ficam disponíveis para explicar sobre as peças. Ressalta-se que o tempo todo da visita, desde a recepção até a despedida o guia esteve sorridente, atento aos comentários de todos, presente com sua perspicácia em fazer brincadeira e analogias construtivas, o que tornou o passeio interativo.

O guia explicou que um percentual do ingresso fica para a comunidade e que esse recurso ajuda a comunidade e o cacique a manter a organização do grupo. Também disse que há pessoas na comunidade que vivem da venda do artesanato nas proximidades, em empreendimentos do turismo como hotéis e no Parque Nacional do Iguazu. Durante as paradas onde haviam outras pessoas da comunidade haviam cestas no chão e o guia pedia para que os visitantes deixassem gorjetas. Em síntese, o turismo desenvolvido na comunidade M'Bororé depende essencialmente da comercialização das agências e operadoras, sendo que um percentual do ingresso fica na comunidade, portanto, a gestão não está sob total autonomia da comunidade, logo não se enquadra nas premissas do turismo comunitário.

\subsubsection{Comunidade Indígena Yriapu}

A palavra Yriapu em Guarani significa barulho das águas. A comunidade vive numa área de 265 hectares assegurada e faz parte da área do Parque Nacional do Iguaçu. Localiza-se em ponto estratégico para o turismo, isto é, a 500 metros da estrada principal de fluxo de turistas (Rodovia das Cataratas de Puerto Iguazu), característica que facilita o acesso de visitantes.

De acordo com o guia, na comunidade atualmente vivem 85 famílias, totalizando cerca de 500 pessoas. Cada família recebe do Estado Argentino o equivalente a seiscentos pesos de auxílio para alimentação. A economia da comunidade provém do artesanato e do turismo, também praticam a agricultura e a caça de animais com as armadilhas. $\mathrm{O}$ artesanato também é comercializado em hotéis próximos e nos atrativos turísticos locais.

O guia relatou que o turismo já existia na comunidade. Contou que havia uma empresa que trazia visitantes, mas eles se sentiam abusados por essa, pois apenas $20 \%$ do valor do ingresso ficava para a comunidade. A organização para a autogestão do turismo começou em 2005 através do "Projecto Mate" - um modelo argentino para Turismo e Emprego, que atua com as frentes sociais. Uma de suas linhas de ação visa aumentar as oportunidades de emprego aos jovens em situação de pobreza. Trata-se de um caminho para a autogestão dos recursos turísticos e culturais da comunidade. O projeto foi desenvolvido pela Agência Canadense de Desenvolvimento Internacional, que conta com apoio do Colégio Comunitário Niagara College de Ontário (Canadá) e Instituto Tecnológico Iguassu (ITEC). Abaixo seguem explicação extraída do site do projeto (http://www.proyectomate.org):

El Modelo MATE apunta al desarrollo de la capacidad laboral potencial de las comunidades indígenas cercanas a las Cataratas del Iguazú, a través de la generación de actividades culturales y del ejercicio de un turismo justo, ambientalmente sustentable y socialmente responsable. La propuesta surgió de intensas consultas con líderes políticos y espirituales del pueblo Mbyá. Se basa en el principio de que la búsqueda del bienestar de las familias indígenas debe estar acompañada por el fortalecimiento de la vida comunitaria, el rescate de los valores culturales ancestrales y la preservación del ambiente selvático, condición esta última sin la cual es inviable la supervivencia del Ñande Rekó, la manera de ser y de vivir de esta antigua nación originaria. 
Os cursos ofertados na comunidade para organização do turismo comunitário tiveram o respaldo do Ministério de Educação e Cultura da província de Misiones e o aporte docente do ITEC, além de profissionais da Administração de Parque Nacionais, Fundação Vida Silvestre Argentina. O projeto encerrou-se em 2012 e seus resultados reverberam até hoje, pela sustentabilidade nutrida através do turismo comunitário desenvolvido pela comunidade. Além disso, durante o projeto foram realizados diversos vídeos com foco em salvaguardar a memória da comunidade guarani, com reportagens e aulas com os mais velhos indígenas. $\mathrm{O}$ projeto também contribuiu financeiramente com a construção do centro de visitantes.

O guia esclareceu que foi realizado um trabalho longo para que eles pudessem desenvolver essa habilidade de comunicação com o não-indígena (branco). Segundo ele, foram quatro anos de trabalho com oficinas para desenvolver a expressão e comunicação corporal e oral. Contou que haviam atividades onde eles tinham que trabalhar a projeção da voz, pois o guarani costuma falar baixinho e na condução de um grupo é necessário manter um tom de voz mais elevado. O projeto Mate também estruturou toda a comercialização e comunicação do projeto: logomarca, fanpage, fotografias, site, articulação para promoção do atrativo, entre outras.

A comunidade recebe visitante todos os dias das $08 \mathrm{~h}$ às $18 \mathrm{~h}$. Em baixa temporada costumam receber em uma semana cerca de 50 pessoas. As escolas regionais costumam agendar as visitas. Essas ocorrem com maior frequência nos meses de agosto e setembro. $\mathrm{O}$ valor é diferenciado para esse público, sendo cobrado cem pesos argentinos de cada aluno (R\$ 20,00). Os demais turistas chegam sem agendamento. O guia contou que já atendeu grupos de até 30 pessoas. $\mathrm{O}$ valor do ingresso é distribuído da seguinte forma: $25 \%$ para a comunidade e $25 \%$ para o empreendimento pagar quem faz a limpeza, cuida das plantas e cuida dos espaços. E 50\% é dividido entre os guias/trabalhadores. Atualmente há três guias, um cobrador e um administrador. De acordo com o guia, todos os condutores são homens, pois as mulheres são mais tímidas, ficam com a parte do artesanato.

Se o visitante desejar ter outra experiência na comunidade, eles oferecem passeios com alimentação. Trata-se da opção de passeio completo com comida típica, mas somente sob agendamento. Este tem o custo de trezentos pesos por pessoa $(\mathrm{R} \$ 60,00)$. A comida oferecida é: reviro feito com farinha de milho, galinha caipiria, chipa e bojapé (pãozinho guarani) e para beber é servido sucos de banana e de abacaxi, pois há muitas dessas frutas na comunidade. Toda a refeição é preparada e servida no centro de visitante.

A chegada na comunidade dispõe de uma pequena área receptiva com bancos e mapa. Ao chegar o guia se apresentou, agradeceu a vinda dos visitantes, e reuniu a todos para explicar como funcionava a visitação na comunidade utilizando um mapa ilustrativo e esclarecendo as diferenças entre as três opções de passeios, a saber: Opção 1: Passeio por áreas da comunidade onde é possível conhecer pontos como centro de visitante, moradias e feira de artesanato, passeio realizado em acompanhamento do guia $-\$ 50,00$ ou $\mathrm{R} \$ 10,00$; opção 2: Passeio com guia pela mata conhecendo algumas armadilhas, centro de visitante e artesanato (duração de 1hora) - \$150,00 pesos ou R \$30,00 e opção 3: Passeio completo com guia, onde é possível conhecer todas as armadilhas, a escola, centro de visitante e feira de artesanato (1h30 minutos) - \$200,00 ou R \$40,00.

A maior parte do passeio ocorre em uma trilha com mata fechada. A trilha tem pontos de paradas para explicar sobre algumas árvores, casa típica Guarani e modelos de armadilhas. O guia fez paradas em cerca de 06 armadilhas (trampas): para capturar pássaros grandes, trampa mondé (para Quati e outros animais pequenos), trampa para animais maiores como veados, trampa para tatu, trampa para ensinar as crianças, a primeira utilizado por eles. Em algumas armadilhas, o guia deixava que o visitante experimentasse. Havia uma armadilha 
para "Jaguareté", animais felinos como onça pintada. Evidentemente que hoje o número de onças pintadas é muito menor, por isso não utilizam a armadilha, sendo utilizada anteriormente pelos ancestrais capturavam esse animal para aproveitar apenas a pele, ossos e dentes, não costumavam consumir a carne. Durante a trilha notava-se alguns insetos e pássaros e o guia explicava sobre eles. Respondeu muitas perguntas a respeito do costume da comunidade: como vivem, economia, costumes espirituais, organização para desenvolver o turismo comunitário. Também explicou o significado da parada Juruá, palavra significa (pessoa de fora) e outras palavras que os visitantes demonstravam curiosidade.

O passeio também passa por uma escolinha de capacitação da comunidade, atualmente sem uso. Em seguida, a trilha leva ao centro de visitante. Trata-se de um espaço arejado onde o visitante pode conhecer um pouco mais sobre a comunidade, pois há um pequeno memorial que apresentam as origens dos indígenas. O local dispõe de banheiros para atender ao público feminino e masculino, uma área de descanso (deck voltado para mata). Um pouco mais adiante chega-se ao final do passeio numa pequena feira de artesanato, onde uma mulher indígena com algumas crianças ficam ali para fazer a venda. Os visitantes não conhecem a casa de reza, o guia explicou que a trilha e o roteiro desenvolvido pela comunidade têm como objetivo permitir que o visitante esteja mais em contato com a natureza do que com as famílias. Na comunidade há 06 xamoios e apenas dois xamaios que recebem as pessoas que vem de fora para dar uma benção ou consulta, mas isso não é divulgado. Segundo o guia, a espiritualidade é sagrada e não pode ser comercializada.

A postura do guia demonstra respeito e imprime com verdade do "jeitinho" Guarani. Perguntou nossos nomes, de onde viemos, interagiu com nossas reações e perguntas e se mostrou o tempo todo disponível. Embora houvesse um tempo estipulado para o passeio, o mesmo foi realizado com tranquilidade, diferente da experiência da comunidade M'Bororé onde o guia fica atento o tempo todo com tempo e apressou o encerramento da visita. Em Yriapu, o guia comunicou-se bem em espanhol e quando não sabia uma palavra buscava explicar dando exemplos ou mesmo contava a palavra em guarani. $\mathrm{O}$ guia de forma autêntica imitava os animais e gesticulava para explicar melhor como funcionava as armadilhas ou trampas. Mais tarde, explicou que foi realizado um trabalho longo para que eles pudessem desenvolver essa habilidade de comunicação com o não-indígena (branco). Ao final comentou que pensam em inovar os passeios existentes com novas trilhas e outras atividades. Para o próximo ano irão organizar um novo empreendimento. Pretendem construir um Museu Guarani e expor peças antigas e próprias da cultura, bem como lendas e outros. Também desejam reativar o coral e reunir cerca de 15 pessoas para resgatar danças.

\subsubsection{Aldeia Jacy Porã}

A comunidade Jacy Porã localiza-se em Puerto Iguazu na Argentina e atua com o turismo de outra forma. Diferente das comunidades M'Borore e Yriapu que recebem visitas in loco nas aldeias, a comunidade Jacy Porã integra o empreendimento turístico Parque das Aves, localizado próximo a entrada do Parque Nacional do Iguaçu do lado brasileiro. Trata-se de uma empresa privada que comercializa passeios com foco na contemplação de aves. Como meio de inovação a empresa junto à comunidade desenvolveu um novo produto chamado Forest Experience. Consiste num encontro com os Guarani que preparam uma cerimônia receptiva para compartilhar com os visitantes. De acordo com a empresa, o encontro envolve "cerimônia de boas-vindas, com dança, comida e o cerimonial do tabaco", também inclui jantar preparado pelos indígenas. O produto é comercializado duas vezes por semana e tem custo de $\mathrm{R} \$ 250,00$ por pessoa, sendo restrito para maiores de 18 anos. 
De acordo com informações divulgadas pela empresa promotora, Parque das Aves, o objetivo do produto Forest Experiencie é dar visibilidade a cultura Guarani e gerar fonte de renda para a comunidade, portanto, o empreendimento não visa obter lucro com a experiência, como declaram:

O dinheiro arrecadado retorna para a aldeia de duas maneiras: ao participar do Forest Experience, cada Guarani recebe um pagamento, e uma proporção do dinheiro arrecadado é depositado em um Fundo Guarani, especialmente desenvolvido para que o dinheiro seja empregado, por exemplo, na construção de fontes de água limpa, como um poço artesiano, na criação de abrigos para as reuniões da comunidade, ou até mesmo na compra de um carro para a aldeia. Os membros da aldeia tem autonomia total para determinar como o dinheiro do Fundo Guarani será utilizado. Além disso, os membros da aldeia são consultados para determinar o valor pago para cada participante e para o Fundo Guarani, como também o valor do ingresso. O Parque das Aves não visa lucro com esta experiência, e seu único objetivo é fortalecer a cultura, o orgulho e a saúde da comunidade Guarani. (PARQUE DAS AVES, 2017).

A experiência se dá em meio a mata. A equipe da empresa faz a condução na entrada e saída enquanto os guaranis lidam com todo o processo da cerimônia. Trata-se de um encontro com místico guarani simbolizado pela roda, fogueira, o canto, pela comida típica.

Traçando um breve comparativo entre as diferentes experiências das comunidades indígenas guaranis com o turismo, identificou-se que a visita ofertada na Aldeia do Yriapu é expressa com mais verdade o viver Guarani. Na comunidade M' Borore o visitante também vive uma relação com o Guarani, mas embora a postura do guia seja muito madura para a comunicação com o não-indígena, todo o passeio é desenhado para satisfazer o visitante, de forma mais comercial. Esse procedimento é compreensível visto que o grupo atende visitas agendadas em dois horários por dia em atendimento a operadora de turismo receptiva. Já a forma de inserção no turismo da Comunidade Jacy Porã ao compor um produto turístico em parceria com o empreendimento consolidado de turismo chama atenção visto que, embora não atenda aos princípios do turismo de base comunitária, ocorre que a comunidade concordou em desenvolver a parceria e também demonstra a disposição em nutrir essa relação com o nãoindígena.

Considerando as premissas do turismo comunitário que propõe autogestão (comunidades protagonistas da atividade), a conservação ambiental, a valorização dos elementos culturais, e a "autogestão sustentável dos recursos patrimoniais comunitários, de acordo com as práticas de cooperação e equidade no trabalho e na distribuição dos benefícios gerados pela prestação dos serviços turísticos" (MALDONADO, 2009, p.31), e as visitas realizadas as comunidades, observou-se que a Comunidade Yriapu melhor atende esses princípios.

Em resumo, as três experiências confluem com as críticas de Comaroff e Comaroff (2001) sobre a comodificação da cultura, uma vez que essas passam a usar ferramentas técnicas $^{11}$ (como redes sociais, plataformas on line) para se colocarem na lógica da competitividade do mercado. No entanto, na perspectiva antropológica, pode-se destacar a relação que se estabelece entre os "outros". O turismo comunitário pode implicar na desconstrução da fria relação sujeito-objeto (consumidor-produtor). Assim, como a antropologia evolui na sua forma de análise rompendo a ideia do observado enquanto objeto

\footnotetext{
${ }^{11}$ A comunidade M'Borore dispõe de informações na operadora, bem como no Tripadvisor. A Comunidade Yriapu dispõe de página na Rede Social do Facebook, e a comunidade Jacy Porã é divulgada através do Parque das Aves.
} 
(GEERTZ, 1989), também se defende no turismo comunitário que a relação entre turistas e comunidade seja uma relação autêntica entre sujeito-sujeito, uma vez que as premissas da atividade defendem a construção de uma relação entre visitante e comunidade baseada na troca, (REDTURS, 2017).

Identifica-se que os resultados dessas interações sociais são fundamentados pela intencionalidade seja de quem o pratica, que pode variar da mera curiosidade em contemplar o diferente, até o interesse de partilhar e conhecer o universo do "outro". Também vem à tona a intenção das comunidades ao receber os visitantes, as quais podem ser motivadas pela sobrevivência, pela valorização da memória, afirmação da identidade, pois ao resgatarem algumas tradições e ao contar por diversas vezes sua história é comum manifestar-se o sentimento de orgulho, na medida em que ocorre uma valorização de suas práticas e costumes. Porém, independentemente da intencionalidade, é inegável que as visitações geram mudanças nas comunidades. Ao compartilharem suas vidas com os turistas estão promovendo alterações em suas percepções tanto na forma de ver e entender a sociedade, bem como na maneira de se ver enquanto membro do grupo e da sociedade em si.

Segundo Parsons (1999) a cultura é um sistema de símbolos e significados e intervir nesse processo requer cuidado, visto que não se pode mistificar ou recriar a cultura para enquadrá-la como produto/mercadoria, e tampouco criar adjetivos para tornar as comunidades atratividades. Por outro lado, o turista também recebe "algo" dessa relação. O que resulta desse encontro para quem visita? Beyaut (1994, p. 196) afirma que a verdadeira integração cultural ocorre nas manifestações espontâneas, sendo essas também "consumo e intercâmbio entre as distintas partes na América Latina".

\section{Considerações finais}

O presente artigo buscou construir um debate acerca do turismo comunitário tendo como motivador a reflexão de como tal atividade implica na condição e no futuro das comunidades tradicionais e indígenas frente ao capital e a globalização.

A pesquisa identificou que os mesmos elementos, os ditos graus de humanidade, que antes eram utilizados como uma distinção negativa entre o civilizado e o selvagem, hoje a serviço do capital, são vistos como elementos de atratividade, o dito "exótico/diferente". O turismo se apropria desses elementos e os transforma em produtos e serviços com a finalidade de difusão, comercialização e mundialização. Em decorrência destes fatores, a atividade turística é reconhecida como uma ferramenta para organização econômica e social dessas comunidades, atuando muitas vezes como principal instrumento de sustentação econômica, por meio da comercialização de produtos e serviços. Na América Latina treze países latinoamericanos se uniram num movimento independente de rede e criaram a REDTURS para fomentar o turismo comunitário. Identificou-se que países como Equador, Costa Rica e Venezuela apresentaram avanços com a criação de políticas públicas para o turismo comunitário num exercício de reconhecimento das comunidades. No Peru, Bolívia, Argentina e Brasil a atividade foi incluída nos planos estratégicos do Estado.

Em paralelo, para que o turismo não atue apenas como expropriador dos elementos culturais das comunidades é necessário que ocorra uma transformação social positiva e não seja nutrida apenas a visão econômica. Para tanto, o diálogo entre os diversos atores envolvidos (Estado, empresas, ONG's, comunidades e outros) demanda aprofundamento, numa construção onde os protagonistas sejam as próprias comunidades. Isso requer uma visão mais abrangente e cautelosa uma vez que o turismo interfere diretamente no desenvolvimento social, simbólico, cultural e econômico das populações onde atua. 
É evidente a relação do turismo comunitário com os processos culturais das comunidades onde atuam, por meio da utilização dos aparatos culturais como principal mercadoria a ser oferecida aos turistas. Deve-se observar e minimizar ao máximo o processo de aculturação desta, para não acabar de forma contrária, ao invés de preservar a cultura local, se transforma em um teatro e na utilização indevida de seus elementos culturais, apenas como mercadoria.

O capital sempre utilizará de diversas formas para a sua manutenção, por tanto a absorção pelo capital das referências culturais dos povos tradicionais e indígenas, deve ser mantida sempre em suspeição, objetivando o correto manejo desta exploração, com foco no mínimo de interferências externas nos reais trânsitos culturais vivenciados pelas comunidades.

\section{Referências}

BENEDICT, R. A Ciência do Costume In Padrões de Cultura. 1 ed. Lisboa: Editora Livros do Brasil. 2000.

BEYHAUT, G. Dimensão cultural da integração da América Latina. Estudos avançados. São Paulo., v. 8, n.20, p.183-198, 1994.

BOAS, F. Cuestiones Fundamentales de Antropología Cultural. Buenos Aires: Ediciones Solar y Librería Hachette S.A.1964.

BRASIL, Governo Federal. Política Nacional de desenvolvimento sustentável dos povos e comunidades tradicionais. Disponível em: <htpp://www.planalto.gov.br/Ccivil_03/_ato20072010/2007/decreto/d6040.htm>. Acesso em: 12 nov. 2016.

Instituto do Patrimônio Histórico e Artístico Nacional. Convenção para a Salvaguarda do Patrimônio Cultural Imaterial. Paris, 17 out. 2003. Disponível em: < http://portal.iphan.gov.br/uploads/ckfinder/arquivos/ConvencaoSalvaguarda.pdf>. Acesso em: 12 nov. 2016.

CANCLINI, N. G. Definiciones en transición. In: MATO, D. Cultura, política y sociedade: perspectivas latinoamericanas. Buenos Aires: CLACSO (Consejo Latinoamericano de Ciencias Sociales), 2005.

CANCLINI, N. G. Definiciones em transición. In: MATO, D. Estudios latinoamericanos sobre cultura y transformaciones sociales em tiempos de globalización. Buenos Aires: CLACSO (Consejo Latinoamericano de Ciencias Sociales), 2001.

CARVALHO, B. T; GOIANA FILHO, J. E. A. O papel da cultura nos processos de integração regional: o caso da UNILA. In: $3^{\circ}$ Encontro Nacional ABRI 2001, 2011, São Paulo. Disponível em:<http://www.proceedings.scielo.br/scielo.php?script=sci

_arttext\&pid=MSC0000000122011000100033\&lng=en\&nrm=abn>. Acesso em: 13 ago. 2016.

CERTEAU, M. A cultura no plural. Tradução Enid Abreu Dobránszky. Campinas: Papirus, 1995. 
CEPAL- Comissão Econômica para a América Latina e o Caribe. Os povos indígenas na américa latina: Avanços na última década e desafios pendentes para a garantia de seus direitos. Santiago, fev. 2015. Disponível em: <http://repositorio.cepal.org>. Acesso em: 13 ago. 2016.

CEPAL- Comissão Econômica para a América Latina e o Caribe. Turismo y condiciones sociales en centroamérica: las experiencias en Costa Rica y Nicaragua. México, 4 jun. 2007. Disponível em: http://www.cepal.org/publicaciones.pdf. Acesso em: 18 jul. 2016.

Os povos indígenas na américa latina - Avanços na última década e desafios pendentes para a garantia de seus direitos. Impresso em Santiago, Chile, 2015. Disponível em: 〈http://repositorio.cepal.org>. Acesso em 15 de abril de 2017.

COMAROFF J; COMAROFF; J. Etnicidad S.A. Traduzido por Carolina Frisman y Elena Marengo. Kartz Editores. Primeira edicíon, 2011.

CORIOLANO, L. N. Turismo: prática social de apropriação e de dominação de territórios. In: LEMOS, A. I. G.; ARROYO, M.; SILVEIRA, M. L. América Latina: Cidade, campo e turismo. São Paulo: CLACSO (Consejo Latinoamericano de Ciencias Sociales), 2006.

DE LA TORRE, O.P. El turismo, fenómeno social. 7 ed. México: Fondo de Cultura Económica, 1992.

GEERTZ, C. A Interpretação das Culturas. 1 ed. Rio de Janeiro: Editora Guanabara, 1989.

GRÜNEWALD, R. Turismo e Etnicidade. Horizonte antropológico, Porto Alegre, v.9, n.20, p. 141- 149, 2003.

GOVERNO DO CHILE. Servicio Nacional del Turismo. Disponível em: https://www.sernatur.cl. Acesso em 10 de maio de 2017.

GOVERNO DA COLOMBIA. Disponível em: http://fontur.com.co/productos-yservicios/turismo-comunitario/21. Acesso em 10 de maio de 2017.

GOVERNO DO VENEZUELA. Ley Orgánica de Turismo - Leyes decretadas por el Presidente Nicolás Maduro para proteger al pueblo, mediante el poder habilitante otorgado por la Asamblea Nacional el 8 de octubre de 2013. Decreto № 1.441.

LABURTHE, P; WARNIER, JP. Etnologia-Antropologia. 3 ed. Petrópolis: Vozes, 2003.

LAPLANTINE, F. Aprender Antropologia. 1 ed. São Paulo: Brasiliense, 2003.

LEAL, R. E. S. O turismo desenvolvido em terras indígenas sob o ponto de vista antropológico. In: BARTHOLO, R.; SANSOLO. D.G.; BURSZT N. Turismo de Base Comunitária: diversidade de olhares e experiências brasileiras. Rio de Janeiro: Letra e imagem, 2009. 
LESSA, M. L. Mercosul Cultural: desafios e perspectivas de uma política cultural. Mural Internacional. Rio de Janeiro, v.1, n.2, p. 50-58, 2010.

MALDONADO, C. O Turismo rural comunitário na América Latina. In: BARTHOLO, R.; SANSOLO. D.G.; BURSZT N. Turismo de Base Comunitária: diversidade de olhares e experiências brasileiras. Rio de Janeiro: Letra e imagem, 2009.

PARQUE DAS AVES. Forest Experience. Disponível em: http://parquedasaves.com.br/xp/pacote/forest-experience/3. Acesso em 12 de maio de 2017.

PARSONS, T. El sistema social. Madri: Alianza Editorial, 1999.

PROJECTO MATTE. Yriapu. Disponível em: http://www.proyectomate.org/turismo.php. Acesso em 12 de maio de 2017.

REDE DE TURISMO COMUNITÁRIO DA AMÉRICA LATINA. Disponível em: http://www.redturs.org/. Acesso em 10 de agosto de 2016.

SALAZAR, N. B. Antropología del turismo en países en desarrollo: análisis crítico de las culturas, poderes e identidades generados por el turismo. Traducción del manuscrito en inglés de María Luisa Valencia. Universidade da Pensilvânia - Estados Unidos, 2006. Disponível em: <http://www.scielo.org.co/pdf/tara/n5/n5a06.pdf>. Acesso em 20 de maio de 2016.

SCHERER-WARREN, I. Redes Sociais: trajetórias e fronteiras. In: SILVEIRA Leila Christina; SILVEIRA, Leandro Lima da. Redes, sociedades e territórios. Santa Cruz do Sul: EDUNISC, 2007.

UNESCO (United Nations Educational, Scientific, and Cultural Organization). Curso virtual sobre registro e inventario del patrimonio cultural inmaterial. s/n, 2010.

WALSH, C. Interculturalidad y decolonialidad: las insurgencias político-epistêmicas de refundar el Estado. Tábula Rasa. Bogotá, v.1, n.9, p.131-152, 2008. 